\title{
Minocycline protects against hepatic ischemia/reperfusion injury in a rat model
}

\author{
YINING LI ${ }^{1}$, TAO LI $^{1}$, HAIZHI QI ${ }^{1}$ and FANG YUAN ${ }^{2}$ \\ ${ }^{1}$ Organ Transplantation Center; ${ }^{2}$ Department of Nephrology, Second Xiangya Hospital, \\ Central South University, Changsha, Hunan 410011, P.R. China
}

Received September 26, 2014; Accepted October 22, 2014

DOI: $10.3892 /$ br.2014.381

\begin{abstract}
Hepatic ischemia/reperfusion (I/R) injury is a common clinical problem. The present study was conducted to investigate the protective effect and mechanism of minocycline (Mino), a tetracycline with anti-inflammatory and antioxidant properties, on $\mathrm{I} / \mathrm{R}$ injury of liver in rats. In total, 54 male Sprague-Dawley rats were randomly divided into 3 groups with 18 rats in each: Sham-operated (control group), I/R model (I/R group) and Mino preconditioning groups (Mino group). The rats of the Mino group were administered Mino (45 mg/kg) by gastric irrigation at $36 \mathrm{~h}$ before surgery and were subsequently administered with $22.5 \mathrm{mg} / \mathrm{kg}$ every $12 \mathrm{~h}$ for the $36 \mathrm{~h}$ before surgery. The rats were sacrificed at 2, 6 and $24 \mathrm{~h}$ after reperfusion, and the serum levels of alanine aminotransferase (ALT), aspartate aminotransferase (AST) and lactate dehydrogenase (LDH) were measured. Hematoxylin/eosin staining of liver tissues was performed to detect the rat liver histological changes and the grade of liver I/R injury (Suzuki's criteria); the levels of malondialdehyde (MDA) and myeloperoxidase (MPO) were determined by spectrophotometry; hepatic tumor necrosis factor- $\alpha(T N F-\alpha)$ and interleukin-1 $\beta(I L-1 \beta)$ mRNA were measured by quantitative polymerase chain reaction; the Dickkopf-1 (DKK-1) and $\beta$-catenin gene products of the liver were detected by western blot analysis. Mino treatment significantly ameliorated the I/R injury of the liver, as shown by decreased Suzuki scores and liver function (ALT, AST and LDH). After 2, 6 and $24 \mathrm{~h}$ reperfusion, compared to the I/R group the MDA and MPO levels of the Mino group decreased in the liver tissues and the levels of hepatic $T N F-\alpha$ and $I L-1 \beta$ mRNA were decreased too. The protein expression of hepatic DKK-1 decreased, whereas $\beta$-catenin
\end{abstract}

Correspondence to: Professor Fang Yuan, Department of Nephrology, Second Xiangya Hospital, Central South University, 139 Renmin Road, Changsha, Hunan 410011, P.R. China

E-mail: yuanfang2011@gmail.com

Key words: minocyclin, hepatic ischemia/reperfusion injury, inflammation, Wnt $/ \beta$-catenin signaling pathway increased, which indicates that the $\mathrm{Wnt} / \beta$-catenin pathway has been activated. In conclusion, Mino protects the liver from I/R injury mainly through reducing oxidative stress and inhibiting the release of pro-inflammatory cytokines by activating the $\mathrm{Wnt} / \beta$-catenin signaling pathway in the liver.

\section{Introduction}

Hepatic ischemia/reperfusion (I/R) injury is a major cause of liver dysfunction and is a common consequence of liver surgery, particularly following hepatectomy and liver transplantation. The restoration of the blood supply following a period of ischemia or lack of oxygen will generally cause I/R injury. Systemic low-flow ischemia and hypoxia, such as trauma, hemorrhagic shock, sepsis, congestive heart failure and respiratory failure, may also lead to hepatic I/R injury. Hepatic $\mathrm{I} / \mathrm{R}$ injury can make patients prone to lethal complications of liver diseases (1), involving numerous pathophysiological processes, such as an increase in inflammatory mediators and cytokines, Kupffer cell activation and release of oxygen free radicals $(2,3)$. The prevention and treatment of hepatic $I / R$ injury is an important clinical problem, which can help with the treatment of severe liver disease and improve the outcome of liver transplantation.

Preconditioning has a significant preventive effect on hepatic I/R injury by inducing the endogenous protective mechanism of cells $(4,5)$. This includes ischemia, pharmacological and ozone oxidative preconditioning. Ischemia preconditioning is limited due to its safety, operability and the individual differences of patients. Pharmacological modulation may currently have a more universal application. Characteristics include more safety, simple operation, no other specialist instrument required and ease of facility, and it has become of current interest in recent years (6).

Minocycline (Mino) is a semisynthetic tetracycline antibiotic that exhibits anti-inflammatory, antiapoptotic, antioxidant and immunosuppression properties (7). Previous studies have reported that Mino has protective effects in the kidney, brain and retinal I/R injury (8-10). However, the effect of Mino on liver I/R injury remains unknown. In the present study, the aim was to evaluate the hepatoprotective effect of Mino on rat I/R liver injury and investigate the underlying mechanism, providing novel insights into Mino treatment for I/R liver injury. 


\section{Materials and methods}

Animals. The protocols of animal use and care conformed to the Guide for the Care and Use of Laboratory Animals from the National Institutes of Health and were approved by the Animal Care and Use Committee of Central South University (Changsha, Hunan, China). Male Sprague-Dawley rats (250-300 g) were purchased from the Animal Center of the Second Xiangya Hospital, Central South University. The rats were housed under temperature-controlled conditions with a 12-h light/dark cycle and ad libitum access to water and food. The rats were randomly divided into three groups: i) sham-operated group (control group), which isolated the blood vessels of the left and middle liver lobe, but did not clamp, and the abdomen was subseqeuently closed without treatment and medication; ii) I/R model (I/R group) as below; and iii) Mino preconditioning group (Mino group), in which the rats were administered Mino $(45 \mathrm{mg} / \mathrm{kg}$; Sigma, St. Louis, $\mathrm{MO}, \mathrm{USA}$ ) by gastric irrigation at $36 \mathrm{~h}$ before surgery and were subsequently administered with $22.5 \mathrm{mg} / \mathrm{kg}$ every $12 \mathrm{~h}$ for the $36 \mathrm{~h}$ before surgery. Each group comprised 18 rats.

Hepatic I/R injury. The rats underwent hepatic I/R or sham surgery. Partial hepatic ischemia was induced as previously described (11). In brief, the rats were anesthetized with isoflurane. A midline laparotomy was performed and an atraumatic clip (Fine Science Tools, Foster City, CA, USA) was placed across the portal vein, hepatic artery and bile duct to interrupt the blood supply to the left lateral and median lobes $(\sim 70 \%)$ of the liver. After $90 \mathrm{~min}$ of partial hepatic ischemia, the clip was removed to initiate reperfusion. The abdomen was closed with 4-0 silk sutures and the animals were allowed to awaken and were provided free access to food and water. Sham control rats underwent the same protocol without vascular occlusion. Rats were sacrificed at 2, 6 and $24 \mathrm{~h}$ after reperfusion and samples of blood and ischemic lobes were collected for analyses.

Biochemical analysis. Blood was drawn from the postcava and centrifuged at 3,000 $\mathrm{xg}$ for $10 \mathrm{~min}$. Serum was collected and stored at $-20^{\circ} \mathrm{C}$. Levels of alanine aminotransferase (ALT), aspartate aminotransferase (AST) and lactate dehydrogenase $(\mathrm{LDH})$ in the serum were measured with an autobiochemical analyzer (Hitachi, Tokyo, Japan).

Liver samples were obtained from the median lobe, washed in cold saline and quickly placed into $-196^{\circ} \mathrm{C}$ liquid nitrogen during sampling and maintained at $-80^{\circ} \mathrm{C}$ until use. Prior to detection, the samples were first unfrozen at $4^{\circ} \mathrm{C}$ and subsequently homogenized in ice-cold phosphate buffer ( $\mathrm{pH}$ 7.4). The homogenates that were centrifuged at 3,500 $\mathrm{x}$ g for $10 \mathrm{~min}$ at $4^{\circ} \mathrm{C}$ were used to determine the level of malondialdehyde (MDA) and myeloperoxidase (MPO), and were assessed with a spectrophotometer at 532 and $460 \mathrm{~nm}$, respectively. The protein level in the liver homogenates was measured using colorimetric assay kits (Jiancheng Bioengineering, Nanjing, China).

Light microscopic examination. Liver specimens of the left lateral lobe were sectioned, fixed in 10\% (w/v) formalin buffer and embedded in paraffin. The sections were cut into $4-\mu \mathrm{m}$ sections and stained with hematoxylin/eosin for histological
Table I. Suzuki's criteria of hepatic ischemia/reperfusion injury.

\begin{tabular}{llll}
\hline Score & Congestion $(\%)$ & Vacuolization $(\%)$ & Necrosis $(\%)$ \\
\hline 0 & None & None & None \\
1 & Minimal (10) & Minimal (10) & $\begin{array}{l}\text { Single cell } \\
\text { necrosis }\end{array}$ \\
& & Mild $(11 \sim 30)$ & Mild $(<30)$ \\
3 & Mild $(11 \sim 30)$ & Moderate $(31 \sim 60)$ & Moderate $(<60)$ \\
4 & Moderate $(31 \sim 60)$ & Severe $(>60)$ & Severe $(>60)$ \\
\hline
\end{tabular}

examination with a light microscope. The histological severity of I/R injury was graded using Suzuki's criteria (Table I). The quantification of the injured area was conducted in a double-blind manner by involving at least two independent investigators.

Quantitative polymerase chain reaction ( $q P C R)$. RNA was extracted from liver tissues using TRIzol ${ }^{\circledR}$ reagent (Invitrogen Life Technologies, Grand Island, NY, USA) and converted into cDNA as described using the primer oligo(dT)15 and Moloney murine leukemia virus reverse transcriptase (Promega Corporation, Madison, WI, USA) at $42^{\circ} \mathrm{C}$ for $60 \mathrm{~min}$. qPCR was performed with the following specific primers using the SYBR-Green PCR Master mix (Takara, Liaoning, China): Mouse tumor necrosis factor- $\alpha(T N F-\alpha)$ forward, 5'-AGGGTCT GGGCCATAGAACT-3'; and reverse, 5'-CCACCACGCTCT TCTGTCTAC-3'; interleukin-1 $\beta(I L-1 \beta)$ forward, 5'-GCAAC TGTTCCTGAACTCAACT- 3 '; and reverse, 5'-ATCTTTTGG GGTCCGTCAACT-3'; and $\beta$-actin (used as an internal positive control) forward, 5'-CCCATCTATGAGGGTTACGC-3'; and reverse, 5'-TTTAATGTCACGCACGATTTC-3'. The experiments were repeated three times independently under identical conditions. The relative density expressed as a ratio of target genes/ $\beta$-actin is presented in the present study.

Western immunoblot analysis. Ground tissues were lysed with radioimmunoprecipitation assasy buffer, containing $50 \mathrm{mmol} / 1$ Tris- $\mathrm{HCl}(\mathrm{pH} 7.5), 150 \mathrm{mmol} / \mathrm{l} \mathrm{NaCl}, 1 \%$ Nonidet $\mathrm{P} 40,1 \%$ sodium deoxycholate, $1 \%$ inhibitor of phosphatase, $0.1 \%$ protease and $1 \mathrm{mmol} / \mathrm{l}$ phenylmethanesulfonylfluoride. Lysates (20-100 $\mu \mathrm{g}$ of protein per lane) were separated by SDS/PAGE (10\% gels) and transferred on to nitrocellulose membranes. The membranes were incubated with primary antibodies as follows: Dickkopf-1 (DKK-1) rabbit monoclonal antibody (cat. no. ab109416), $\beta$-catenin rabbit monoclonal antibody (cat. no. ab32572) and tubulin rabbit polyclonal antibody(cat. no. ab126165) (Abcam, San Francisco, CA, USA). The filters were washed and incubated with horseradish peroxidase donkey anti-rabbit $\mathrm{Ab}$ (Abcam). Relative quantities of DKK-1 and $\beta$-catenin protein were determined using a densitometer (Kodak Digital Science 1D analysis software; Rochester, NY, USA).

Statistical analysis. All the data were performed with SPSS version 11.5 software (SPSS Inc., Chicago, IL, USA) and expressed as mean \pm standard deviation. Student's t-test was used to evaluate the statistical significance. $\mathrm{P}<0.05$ was considered to indicate a statistically significant difference. 
Table II. Rat serum levels of ALT, AST and LDH in each group after 2, 6 and $24 \mathrm{~h}$ reperfusion.

\begin{tabular}{lccccc}
\hline Index & Groups & No. of rats & $2 \mathrm{~h}$ & $6 \mathrm{~h}$ & $24 \mathrm{~h}$ \\
\hline ALT & Con & 6 & $64.37 \pm 13.65$ & $70.80 \pm 8.11$ & $64.20 \pm 7.49$ \\
ALT & I/R & 6 & $617.33 \pm 69.63^{\mathrm{a}}$ & $1305.60 \pm 255.40^{\mathrm{a}}$ & $270.90 \pm 23.42^{\mathrm{a}}$ \\
ALT & Mino & 6 & $255.90 \pm 28.04^{\mathrm{a}, \mathrm{b}}$ & $516.93 \pm 72.50^{\mathrm{a}, \mathrm{b}}$ & $121.20 \pm 11.10^{\mathrm{a}, \mathrm{b}}$ \\
AST & Con & 6 & $161.57 \pm 26.88$ & $171.35 \pm 25.47$ & $152.08 \pm 21.76$ \\
AST & I/R & 6 & $1524.70 \pm 315.26^{\mathrm{a}}$ & $2488.1 \pm 365.52^{\mathrm{a}}$ & $743.47 \pm 61.59^{\mathrm{a}}$ \\
AST & Mino & 6 & $908.98 \pm 80.40^{\mathrm{a}, \mathrm{b}}$ & $1533.47 \pm 319.70^{\mathrm{a}, \mathrm{b}}$ & $511.20 \pm 45.25^{\mathrm{a}, \mathrm{b}}$ \\
LDH & Con & 6 & $256.23 \pm 32.11$ & $311.70 \pm 56.72$ & $258.30 \pm 37.18$ \\
LDH & I/R & 6 & $2467.21 \pm 322.70^{\mathrm{a}}$ & $3601.34 \pm 345.33^{\mathrm{a}}$ & $1909.65 \pm 197.30^{\mathrm{a}}$ \\
LDH & Mino & 6 & $988.67 \pm 103.46^{\mathrm{a}, \mathrm{b}}$ & $1763.98 \pm 579.23^{\mathrm{a}, \mathrm{b}}$ & $879.56 \pm 231.78^{\mathrm{a}, \mathrm{b}}$
\end{tabular}

${ }^{\mathrm{a}} \mathrm{P}<0.05$ vs. control group; ${ }^{\mathrm{b}} \mathrm{P}<0.05 \mathrm{vs}$. I/R group. Data are mean \pm standard deviation, U/l. ALT, alanine transaminase; AST, aspartate transaminase; $\mathrm{LDH}$, lactate dehydrogenase; Con, control sham-operated group; I/R, ischemia/reperfusion; Mino, minocycline.

Table III. Level of MDA and MPO in rat liver tissues following hepatic ischemia/reperfusion at different time point in each group.

\begin{tabular}{|c|c|c|c|c|c|}
\hline Index & Groups & No. of rats & $2 \mathrm{~h}$ & $6 \mathrm{~h}$ & $24 \mathrm{~h}$ \\
\hline MDA & Con & 6 & $4.07 \pm 1.21$ & $4.25 \pm 1.02$ & $4.01 \pm 1.36$ \\
\hline MDA & IR & 6 & $16.81 \pm 4.17^{\mathrm{a}}$ & $27.43 \pm 5.09^{a}$ & $14.95 \pm 2.31^{\mathrm{a}}$ \\
\hline MDA & Mino & 6 & $9.52 \pm 2.14^{\mathrm{a}, \mathrm{b}}$ & $15.23 \pm 2.97^{\mathrm{a}, \mathrm{b}}$ & $8.47 \pm 1.91^{\mathrm{a}, \mathrm{b}}$ \\
\hline MPO & Con & 6 & $1.01 \pm 0.98$ & $1.98 \pm 1.20$ & $0.96 \pm 3.17$ \\
\hline MPO & IR & 6 & $5.31 \pm 5.47^{\mathrm{a}}$ & $7.28 \pm 1.76^{\mathrm{a}}$ & $4.96 \pm 2.17^{\mathrm{a}}$ \\
\hline MPO & Mino & 6 & $2.98 \pm 0.79^{\mathrm{a}, \mathrm{b}}$ & $3.47 \pm 3.70^{\mathrm{a}, \mathrm{b}}$ & $2.20 \pm 4.25^{\mathrm{a}, \mathrm{b}}$ \\
\hline
\end{tabular}

${ }^{\mathrm{a}} \mathrm{P}<0.05$ vs. control group; ${ }^{\mathrm{b}} \mathrm{P}<0.05 \mathrm{vs}$. I/R group. Data are mean \pm standard deviation, $\mathrm{mg}$ of protein $/ \mathrm{ml}$. MDA, methane dicarboxylic aldehyde; MPO, myeloperoxidase; Con, control sham-operated group; I/R, ischemia/reperfusion; Mino, minocycline.

\section{Results}

Levels of ALT, AST and LDH in serum. After reperfusion for 2, 6 and $24 \mathrm{~h}$, the levels of AST, ALT and LDH were higher in the $\mathrm{I} / \mathrm{R}$ and Mino groups compared to the control group at each time point and reached the peak at $6 \mathrm{~h}$ after reperfusion $(\mathrm{P}<0.05)$. Whereas the levels of AST, ALT and LDH in the serum were significantly reduced in the Mino group compared to those in the I/R group (Table II; $\mathrm{P}<0.05$ ).

Effect of Mino on liver antioxidant ability. There were no clear changes of MDA and MPO levels in the control group at each time point. Compared to the control, the MDA and MPO levels increased in I/R group after reperfusion for 2, 6 and 24 h. Following Mino treatment, the MDA and MPO levels were markedly decreased compared to those in the I/R group (Table III; $\mathrm{P}<0.05$ ).

Liver histology in the ischemia model followed by reperfusion. The control group showed no marked abnormalities in liver tissue morphology after reperfusion for 2, 6 and $24 \mathrm{~h}$. The boundaries between liver cell cords and hepatic sinusoids became unclear in the I/R group after $2 \mathrm{~h}$ reperfusion. Furthermore, inflammatory cell accumulation, oncosis and apoptosis of the liver cells were evidently observed after $6 \mathrm{~h}$
Table IV. Suzuki's for each group at different time points.

\begin{tabular}{lccc}
\hline Group & $2 \mathrm{~h}$ & $6 \mathrm{~h}$ & $24 \mathrm{~h}$ \\
\hline Con & 0 & 0 & 0 \\
IR & $5.50 \pm 1.76^{\mathrm{a}}$ & $8.17 \pm 1.33^{\mathrm{a}}$ & $5.50 \pm 2.26^{\mathrm{a}}$ \\
Mino & $3.33 \pm 0.52^{\mathrm{a}, \mathrm{b}}$ & $5.67 \pm 1.37^{\mathrm{a}, \mathrm{b}}$ & $3.33 \pm 0.52^{\mathrm{a}, \mathrm{b}}$
\end{tabular}

${ }^{\mathrm{a}} \mathrm{P}<0.05$ vs. control group; ${ }^{\mathrm{b}} \mathrm{P}<0.05$ vs. $\mathrm{I} / \mathrm{R}$ group. Data are mean \pm standard deviation. Con, control sham-operated group; I/R, ischemia/reperfusion; Mino, minocycline.

of reperfusion in the I/R group. After reperfusion for $24 \mathrm{~h}$, the histopathological changes started to improve. However, in the Mino group, the liver cells had less swelling, remained well arranged and had no clear signs of oncosis and apoptosis; but the hepatic sinusoid was dilated following reperfusion (Fig. 1). Compared to the I/R group, the Suzuki scores decreased in the Mino group in regards to hepatic congestion, vacuolization and necrosis (Table IV).

Levels of TNF- $\alpha$ and $I L-1 \beta m R N A . T N F-\alpha$ and $I L-1 \beta$ levels at 2, 6 and $24 \mathrm{~h}$ after reperfusion were significantly increased in the $\mathrm{I} / \mathrm{R}$ and Mino groups compared to the control group $(\mathrm{P}<0.05)$. 


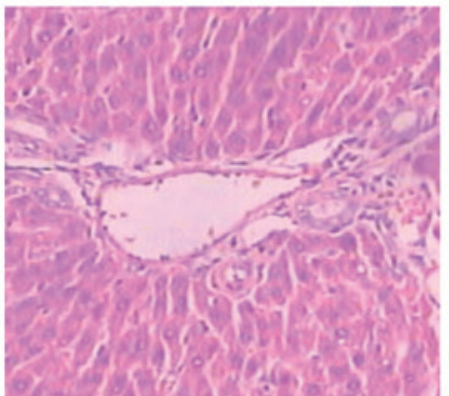

Control group

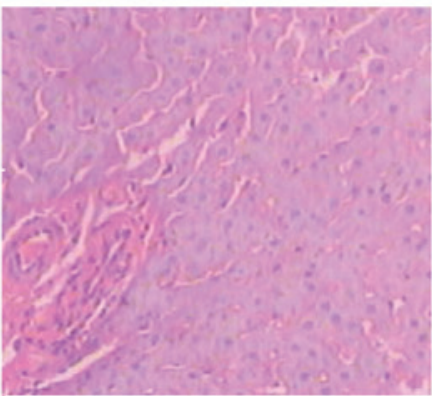

I/R group $2 \mathrm{~h}$

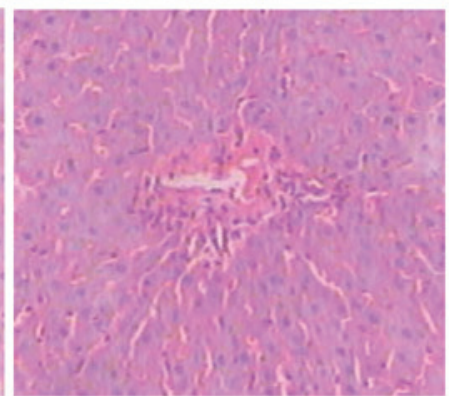

I/R group $6 \mathrm{~h}$

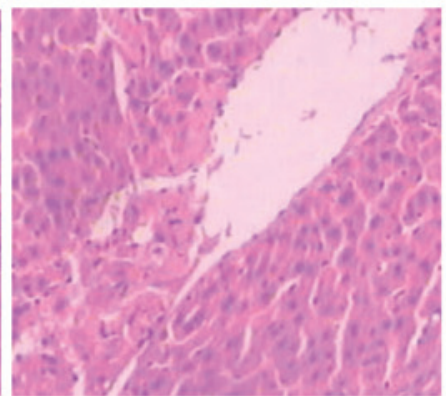

I/R group $24 \mathrm{~h}$

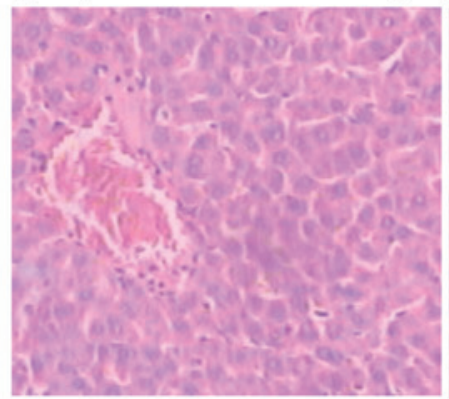

Mino group $2 \mathrm{~h}$

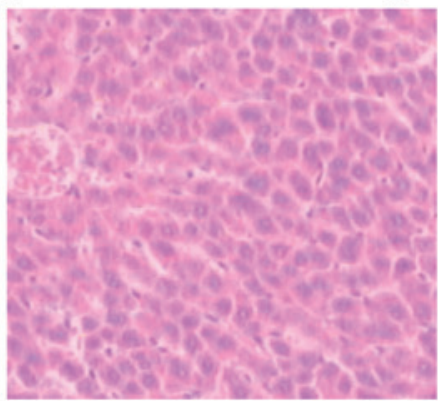

Mino group $6 \mathrm{~h}$

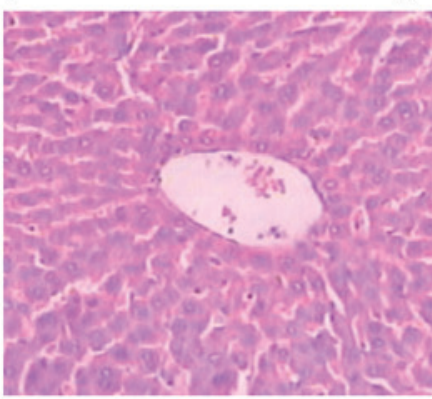

Mino group $24 \mathrm{~h}$

Figure 1. Pathology changes in rat hepatic tissue at different times in each group (hematoxylin/eosin, x200 magnification). Con, control sham-operated group; $\mathrm{I} / \mathrm{R}$, ischemia/reperfusion; Mino, minocycline.

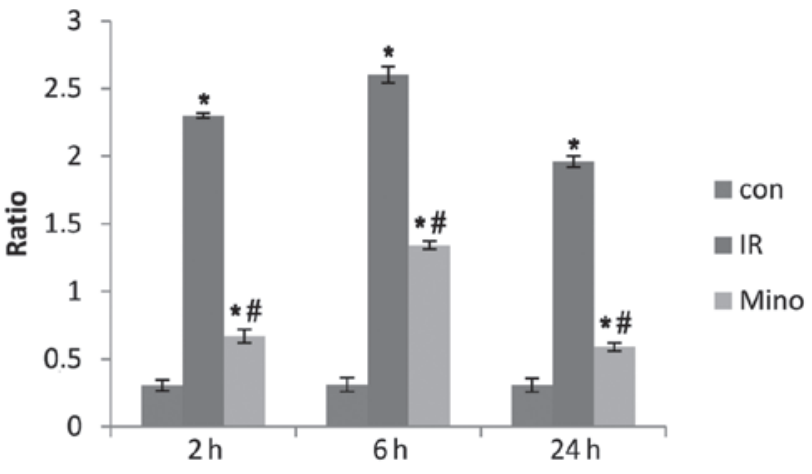

Figure 2. Expression of tumor necrosis factor- $\alpha$ mRNA in the liver tissues of each group after reperfusion for 2, 6 and $24 \mathrm{~h}$. Con, control sham-operated group; I/R, ischemia/reperfusion; Mino, minocycline. " $\mathrm{P}<0.05$ vs. control group; ${ }^{\prime} \mathrm{P}<0.05$ vs. I/R group. $\beta$-actin mRNA was considered as the internal control.

However, following treatment with Mino, the mRNA expression of $T N F-\alpha$ and $I L-1 \beta$ decreased compared to the I/R group at each time point (Figs. 2 and 3; $\mathrm{P}<0.05$ ).

Expressions of DKK-1 and $\beta$-catenin in liver tissues. DKK-1 and $\beta$-catenin protein expression of rat liver tissues was detected in each group after $24 \mathrm{~h}$ reperfusion using western blot analysis. The results showed that there was no evident expression of DKK-1 in the control group. The protein expression of DKK-1 was upregulated by $77.8 \%$ in the I/R group, and when compared to the I/R group, it decreased by $44.4 \%$ in Mino group $(\mathrm{P}<0.05)$.

By contrast, the protein expression of $\beta$-catenin was downregulated by $72.2 \%$ in the I/R group compared to the control. Following Mino treatment, it increased by $55.6 \%$ compared to

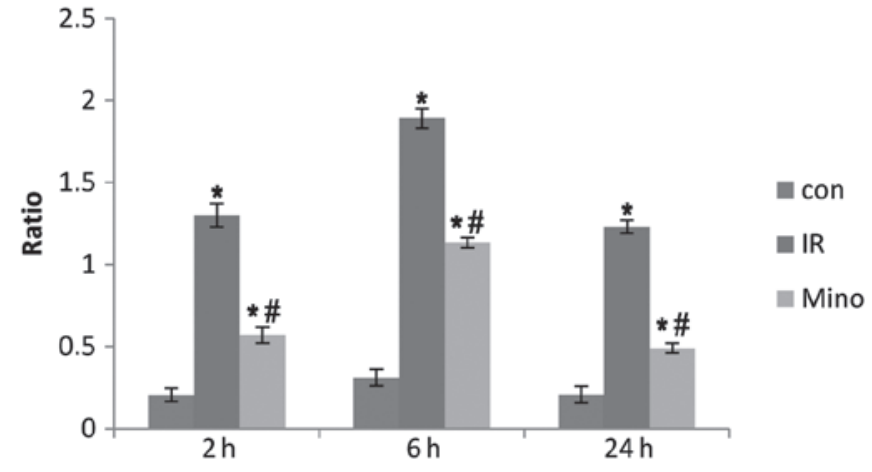

Figure 3. Expression of interleukin-1 $\beta$ mRNA in the liver tissues of each group after reperfusion for 2, 6 and $24 \mathrm{~h}$. Con, control sham-operated group; I/R, ischemia/reperfusion; Mino, minocycline. ${ }^{*} \mathrm{P}<0.05$ vs. control group; ${ }^{\#} \mathrm{P}<0.05$ vs. $\mathrm{I} / \mathrm{R}$ group. $\beta$-actin mRNA was considered as the internal control.

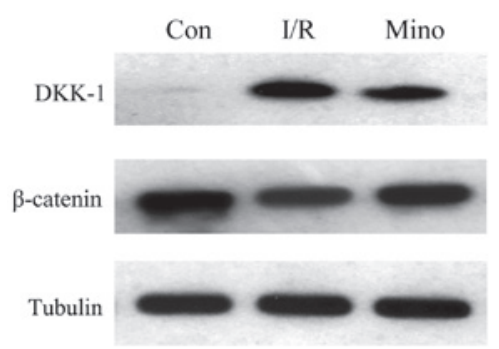

Figure 4. Western blot analysis of Dickkopf-1 (DKK-1) and $\beta$-catenin protein expression in liver tissues. Con, control sham-operated group; I/R, ischemia/reperfusion; Mino, minocycline.

the I/R group, but it remained lower than the control (Fig. 4, $\mathrm{P}<0.05)$. 


\section{Discussion}

Hepatic I/R injury is a complex multifactorial pathophysiological process (12), and it also has a wide range of clinical concern. Studies have shown that pharmacological preconditioning has a significantly preventive effect on hepatic I/R injury. In addition to the antimicrobial actions of Mino, previous studies have demonstrated its cytoprotective potential in a variety of settings, including ischemic cardiac, renal and central nervous system disease. In the present study, hepatic injury after reperfusion for $6 \mathrm{~h}$ was more pronounced compared to 2 and $24 \mathrm{~h}$, which is consistent with the previous study on the rat hepatic I/R model by Zhou et al (13). Furthermore, pretreatment with Mino prior to ischemia and the subsequent reperfusion significantly reduced congestion, edema, vacuolization and necrosis of liver cells and protected the hepatic cells against I/R injury in a rat model. As for the protective effect, there may be a number of essential components participating in the procedure, including MDA, MPO and certain pro-inflammatory cytokines.

The damage to the livercaused by reperfusion is more serious than ischemia. Previous studies have shown that it is mainly the Kupffer cells and complement activation, and aggregation and cluster of differentiation $4^{+}$lymphocytes activation in the early stage of hepatic I/R injury (14). Once the Kupffer cells are activated, they release large amounts of pro-inflammatory cytokines (TNF- $\alpha$ and IL-1), the lipid inflammatory mediators and oxygen free radicals, which mediate liver injury $(15,16)$. As a pro-inflammatory cytokine, TNF- $\alpha$ can result in liver microcirculation disturbance by interacting with neutrophils and endothelial cells. In addition, IL-1 $\beta$ is considered to be a valid target for therapeutic intervention in diseases associated with tissue remodeling (17). Thus, downregulation of the level of $T N F-\alpha$ and/or $I L-1 \beta$ will be beneficial for the alleviation of I/R injury. In the present study, the expression of $T N F-\alpha$ and $I L-1 \beta$ was significantly reduced by Mino, and the levels of serum ALT, AST and LDH decreased in comparison to the I/R group. Therefore, it is speculated that Mino performs its liver protective effect mainly due to the suppression on Kupffer cells, which can further influence the expression of $T N F-\alpha$ and $I L-1 \beta$. Additionally, this decrease in inflammation coincided with a greatly reduced level of MPO in liver tissue, indicating the prevention of neutrophil infiltration into the liver following $\mathrm{I} / \mathrm{R}$ with Mino treatment.

Oxidative stress plays an important role in the development of hepatic I/R injury. Reducing oxygen radicals is one of the goals to intervene the hepatic I/R injury. Due to the presence of the diethyamino group on the phenolic carbon, Mino has a superior scavenging ability (18). MDA and MPO are regarded as the indirect indexes reflecting the levels of oxygen free radical and degree of lipid peroxidation. In the present study, the pretreatment of Mino reduced the MDA and MPO levels in liver tissue and subsequently further improved the antioxidant ability of the liver. The result shows that Mino inhibited liver oxidative damage through its antioxidant ability.

The liver differs from other visceral organs in its innate ability for short-term regeneration (19). Therefore, therapy aimed at stimulating the pathways involved in the proliferation of new hepatocytes to replace dead/damaged cells, or at conditioning cells to respond differently to an ischemic insult, may prove particularly beneficial in cases of hepatic I/R. One crucial pathway in cell replication and regeneration is the $\mathrm{Wnt} / \beta$-catenin signaling axis. Canonical Wnt signaling has been identified as central to embryonic development, progenitor cell differentiation and proliferation of cells arising from all three germ layers $(20,21)$. Additionally, Wnt/ß-catenin signaling has been shown to play a key role specifically in liver development, prevention of apoptosis and protection from metabolic stress (22). $\beta$-catenin, $88 \mathrm{kDa}$, is a dual function protein, regulating the coordination of cell-cell adhesion and gene transcription. DKK-1 is known to be a secreted protein that functions as a negative regulator of Wnt signaling and plays a crucial role in inducing various tumor cells apoptosis. A previous study showed that the Wnt agonist protects against hepatic I/R injury through its known proliferative and anti-apoptotic properties (23).

Funato et al (24) reported the important links between oxidative stress and the canonical Wnt signaling pathway. Essers et al (25) have identified, as a protective reaction, that $\beta$-catenin can bind directly to forkhead box $\mathrm{O}$ (FoxO), enhance FoxO transcriptional activity in mammalian cells and regulate cell cycles, thus reducing the liver damage of oxidative stress. Previous studies have shown that liver damage is mainly caused by energy metabolism and oxidative stress, and oxidative stress is believed to be the initiating factor in I/R injury (26). The results of the present study showed that the expression of $\beta$-catenin in the I/R group was significantly lower compared to the control group, while DKK-1 expression was significantly increased, indicating that the $\mathrm{Wnt} / \beta$-catenin signaling pathway is inhibited during the hepatic I/R injury. Compared to the $\mathrm{I} / \mathrm{R}$ group, the expression of $\beta$-catenin in the Mino group was increased and DKK-1 expression was decreased, the oncosis and apoptosis in liver tissue were reduced, MDA and MPO production was reduced, and $T N F-\alpha$ and $I L-1 \beta$ mRNA expression was downregulated. All these results indicate that Mino protects the liver from I/R injury mainly through reducing oxidative stress and inhibiting the release of pro-inflammatory cytokines by activating Wnt/ $\beta$-catenin signaling pathway in the liver.

In conclusion, Mino has a protective effect on hepatic I/R injury in rats, but whether it has a dose-dependent manner requires further investigation.

\section{References}

1. Subhas G, Gupta A, Bakston D, et al: Protective effect of methylprednisolone on warm ischemia-reperfusion injury in a cholestatic rat liver. Am J Surg 199: 377-381, 2010.

2. Schauer RJ, Kalmuk S, Gerbes AL, et al: Intravenous administration of glutathione protects parenchymal and non-parenchymal liver cells against reperfusion injury following rat liver transplantation. World J Gastroenterol 10: 864-870, 2004.

3. Su JF, Guo CJ, Wei JY, et al: Protection against hepatic ischemia-reperfusion injury in rats by oral pretreatment with quercetin. Biomed Environ Sci 16: 1-8, 2003.

4. Que X, Debonera F, Xie J, et al: Pattern of ischemia reperfusion injury in a mouse orthotopic liver transplant model. J Surg Res 116: 262-268, 2004.

5. Jaeschke H: Reperfusion injury after warm ischemia or cold storage of the liver: role of apoptotic cell death. Transplant Proc 34: 2656-2658, 2002.

6. Jaeschke H: Molecular mechanisms of the hepatic ischemia-reperfusion injury and preconditioning. Am J Physiol Gastrointest Liver Physiol 284: G15-G26, 2003. 
7. Griffin MO, Ceballos G and Villarreal FJ: Tetracycline compounds with non-antimicrobial organ protective properties: possible mechanisms of action. Pharmacol Res 63: 102-107, 2011.

8. Yu XD, Wu XH, Du XW, et al: Protective effects of minocycline on renal ischemia-reperfusion injury in rats. J Chongqing Med Univ 32: 1172-1174, 2007.

9. Plane JM, Shen Y, Pleasure DE, et al: Prospects for minocycline neuroprotection. Arch Neurol 67: 1442-1448, 2010.

10. Abcouwer SF, Lin CM, Shanmugam S, et al: Minocycline prevents retinal inflammation and vascular permeability following ischemia-reperfusion injury. J Neuroinflammation 10: 149, 2013.

11. Zhai Y, Shen XD, O'Connell R, et al: Cutting Edge: TLR4 activation mediates liver ischemia/reperfusion inflammatory response via IFN regulatory factor 3-dependent MyD88-independent pathway. J Immunol 173: 7115-7119, 2004.

12. Xing HC, Li LJ, Xu KJ, et al: Intestinal microflora in rats with ischemia/reperfusion liver injury. J Zhejiang Univ Sci B 6: 14-21, 2005.

13. Zhou JX, Ye QF, Ming YZ, et al: Effects of PNS on expression of nuclear factor- $\kappa \mathrm{B}$ and ICAM-1 in rat liver graft after ischemia reperfusion. Chin J Mod Med 15: 1330-1332, 2005.

14. Fondevila C, Busuttil RW and Kupiec-Weglinski JW: Hepatic ischemia/reperfusion injury - a fresh look. Exp Mol Pathol 74 $86-93,2003$.

15. Thobe BM, Frink M, Hildebrand F, et al: The role of MAPK in Kupffer cell toll-like receptor (TLR) 2-, TLR4-, and TLR9-mediated signaling following trauma-hemorrhage. J Cell Physiol 210: 667-675, 2007.

16. Tsung A, Hoffman RA, Izuishi K, et al: Hepatic ischemia/reperfusion injury involves functional TLR4 signaling in nonparenchymal cells. J Immunol 175: 7661-7668, 2005.

17. Kolb M, Margetts PJ, Anthony DC, et al: Transient expression of IL-1beta induces acute lung injury and chronic repair leading to pulmonary fibrosis. J Clin Invest 107: 1529-1536, 2001.
18. Griffin MO, Fricovsky E, Ceballos G, et al: Tetracyclines: a pleitropic family of compounds with promising therapeutic properties. Review of the literature. Am J Physiol Cell Physiol 299: C539-C548, 2010.

19. Fausto N, Campbell JS and Riehle KJ: Liver regeneration. Hepatology 43 (2 Suppl 1): S45-S53, 2006.

20. Kwon C, Arnold J, Hsiao EC, et al: Canonical Wnt signaling is a positive regulator of mammalian cardiac progenitors. Proc Natl Acad Sci USA 104: 10894-10899, 2007.

21. Masckauchan TN, Shawber CJ, Funahashi Y, et al Wnt/beta-catenin signaling induces proliferation, survival and interleukin-8 in human endothelial cells. Angiogenesis 8: 43-51, 2005.

22. Behari J, Yeh TH, Krauland L, et al: Liver-specific beta-catenin knockout mice exhibit defective bile acid and cholesterol homeostasis and increased susceptibility to diet-induced steatohepatitis. Am J Pathol 176: 744-753, 2010.

23. Kuncewitch M, Yang WL, Molmenti E, et al: Wnt agonist attenuates liver injury and improves survival after hepatic ischemia/reperfusion. Shock 39: 3-10, 2013.

24. Funato Y, Michiue T, Asashima M, et al: The thioredoxin-related redox-regulating protein nucleoredoxin inhibits Wnt-beta-catenin signaling through dishevelled. Nat Cell Biol 8: 501-508, 2006

25. Essers MA, de Vries-Smits LM, Barker N, et al: Functional interaction between beta-catenin and FOXO in oxidative stress signaling. Science 308: 1181-1184, 2005.

26. Goode HF, Webster NR, Howdle PD, et al: Reperfusion injury, antioxidants and hemodynamics during orthotopic liver transplantation. Hepatology 19: 354-360, 1994. 